\title{
GERAKAN SOSIAL MODERN MASYARAKAT ISLAM DI INDONESIA
}

\section{Oleh:}

Wasito*

\begin{abstract}
Abstrak
Artikel ini membahas tentag perkembangan gerakan modernisasi Islam yang terjadi di Indonesia mulai masa pra kemerdekaan hingga masa pasca kemerdekaan. Diantara gerakan-gerakan sosial modern Islam yang ada di indonesia meliputi Gerakan Serikat Islam, Gerakan Muhammadiyyah, dan Gerakan Nahdlatul Ulama. Agama Islam muncul pada Abad ke-6 M kemudian masuk ke Indonesia pada abad ke-7 M dan mulai berkembang pada abad ke-13 M. Perkembangan Islam di Indonesia hampir di seluruh Kepulauan Indonesia. Bertolak dari kenyataan tersebut, Islam banyak menghasilkan peninggalan sejarah yang bercorak Islam di Indonesia yang sangat beraneka ragam. Peninggalanpeninggalan itu antara lain, tempat ibadah, keraton, batu nisan, kaligrafi, seni pahat, seni pertunjukan, tradisi upacara, dan karya sastra.
\end{abstract}

\section{Pendahuluan}

Pada Tahun 70-an-80-an gerakan-gerakan Islam di Indonesia mulai mengalami perubahan yang tidak hanya didominasi oleh gerakan-gerakan pada tahun 20an-30an yang sebelum mengalami kemerdekaan. Gerakan pada tahun yang dimulai dari tahun 70-an sering disebut dengan gerakan kontemporer, yaitu gerakan yang muncul dalam suatu setting kehidupan masyarakat Indonesia yang sedang mengalami proses intensifikasi modernisasi. Dalam konsep teoritis menurut Shiddiqi konsep barat dan Islam mengalami perbedaan yaitu dimana Islam tidak semata-mata mengandung rumusan hubungan probadi antara manusia dengan tuhannya, melainkna

\footnotetext{
* Institut Agama Islam Tribakti (IAIT) Kediri
} 
juga rumusan tentang tatanan social kemasyarakatan, politik dan masih banyak hal lainnya.

Menurut Deliar Noer, terdapat 2 paradigma yaitu Islam tradisional dan Islam modern yang dilihat dari 3 aspek, diantaranya:

- Semangat pemurnian ajaran

- Sikap terhadap tradisi berrmazhab

- Sikap terhadap perubahan dan rasionalitas

Masyarakat Islam Indonesia mulai menyadari perlunya perubahan dalam kemajuan Islam. Kemunculan beberapa gerakan-gerakan di Indonesia untuk merubah konsep gerakan Islam masa lalau dengan gerakan yang memiliki kompetisi lebih baik untuk dapat bersaing, Beberapa gerakan yang lahiir di Indonrsia yaitu : Serikat Islam, Muhammadaiyah, Nahdatul Ulama dan gerakan lainnya yang dapat memajukan Islam. Dalam setiap gerakan memiliki perbedaan cirri-ciri dan konsep sendiri.

\section{Gerakan Sosial Modern Masyarakat Islam Di Indonesia Gerakan Serikat Islam (SI)}

Sebelum menggunakan nama Sarekat Islam, organisasi ini bernama Saarekat Dagang Islam (SDI), yang didirikan oleh Wirjodikoro yang setelah menunaikan ibadah haji bernama Haji Samanhudi di Solo pada akhir 1911. Sebenarnya ada pula sebagian pendapat yang mengatkan bahwa SDI telah berdiri pada tahun 1905. Tujuan SDI adalah memajukan perdagangan, melawan monopoli Toinghoa dan memanjukan Agama Islam. Karena itulah, SDI disebut gerakan nasionalistis-religiusekonomis.

- Perkembangan serikat Islam dibagi menjadi 4 periode, yaitu :

a. Periode 1911-1916

Serikat Islam yang didirikan di Solo pada tanggal 11 November 1911 ini tumbuh dari organisasi yang dahulunya bernama Serikat Daganag Islam( SDI).. Terdapat 2 sebab didirikan organisasi ini, pertama , terjadinya kompetisi yang meningkat dakam bidang perdagangan batikt erutama dengan golongan Cina dan sikap superioritas orang-orang Cina terhadap 
orang Indonesia dengan sehubungnya keberhasilan revolusi Cina(1911).

SI di Solo dengan tujuan menjadikan benteng bagi orang-orang Indonesia yang umumnya pedangang batik.Periode pertama ini ditandai permasalahan-permasalahan organisasi termasuk mencari pemimpin, penyusun anggaran dasar dan hubungan antar organisasi pusat dengan organisasi daerah. Hal itu berhasil dilakukan sehingga jalan itu berhasil samapi mencapai tahun 1916-1921., Si banyak didirikan disetiap daerah-daerah yang ada di Indonesia.

b. Periode 1916-1921

Organisasi periode ini mengalami sedikit kestabilan sebab Si banyak memperhatikan masalah-masalah yang terjadi, pertemuan-pertemuan yang dilakukan saat itu disebut kongres saja dan kongres nasional .

Menjelaskan pemakaian kata "nasional", Tjokroaminoto berkata bahwa ia merupakan suatu usaha untuk "meningkatkan" seseorang pada tingkat natie (bangsa) usaha pertama untuk berjuamg menunt pemerintah sendiri atau sekurang-kurangnya agar orang-orang Indonesia diberikan hak untuk mengemukakan suaranya dalam masalah-masalah politiknya.

Sifat pollitik dari Si ini dirumuskan dalam" Keterangan Pokok"(Asas) dan Program kerja. Pokok ini mengemukakan kepercayaan Central SI bahwa "agama Islam itu membuka rasa pikiran prihal persamaan derajat manusia sambil menjunjung tinggi kepada kuasa negri" dan bahwasanya Islam sebaikbaiknya agama buat mendidik budi pekertinya rakyat. Dalam mencapai maksud dan tujuan ini Central SI mencari kerjasama dan saling membantu dengan pihak-pihak yang menyetujuinya

c. Periode 1921-1927

Merupakan suatu perubahan SI didalam perkembangannya: pertama, dijumpai perubahan pada Keterangan Asas dari partai. Kedua dicatat suatu perpecahan dengan kalangan PKI.

Ketiga ialah penahanan terhadap Tjokroaminoto oleh pemerintah yang menyebabkan alasan utama untuk mengambil "polotik hijrah" pada tahun berikutnya. Penahanan ini merupakn kejadian yang sangat berpengaruh bagi perkembanganya partai 
d. Periode 1927- 1942.

Dalam tahun 1927 periode transisi untuk mendirikan Partai Sarekat Islam dan menghapuskan striktur lama selesai. Ini tidak berarti bahwa dalam periode trakir ini masalah-masalah stuktur tidak lagi dipersoalkan. Tetapi perhatian lebih banyak ditujukan kapada persoalan -persoalan teori dan falsafah seperyi yang tercermin oleh Tafsir Asas dan Politik Hijrah, dibandingkan dengan periode sebelumnya. Suatu penyebab lain yang menyebabkan pecahnya SI adalah keputusannya pada tahun 1927 untuk mengeluarkan semua anggota-anggota Muhammadiyah dari lingkungannya.

Pembentukan PNI oleh Sukarno menantang kedudukan SI ataupun kepemimpinan Islam umumnya dalam rangka pergerakan perjuangan kemerdekaan. Posisi yang penting sari pemimpin-pemimpin PNI di dalam pergerakan kemerdekaan menyebabkan terjadinya dua sayap di dalm lingkungan gerakan itu, yaitu nasionalis Islam disatu pihak, dan nasionalis yang netral agama dipihak lain.

- Dasar Sarekat Islam

Berpangkal pada keyakinan bahwa agama Islam adalah agama Allah, perumusan asas mengingatkan pada ketuhanan dan kesucian Quran, dan bahwa dengan ini, bila umat berpegangan kepadanya, persatuan akan dapat terwujud.

Pemerintah yang dicita-citakn oleh partai ini ialah pemerintah "yang kekuasaannya bersandar pada kemauan rakyat, yang menyatakan sepenuhnya suaranya dalam suatu Majelis Syura, berupa Majelis Permusyawaratn Rakyat, majelis Parlemen atau lain-lainnya serupa itu, yang susunannya harus bersandar atas dasar asas-asas demokrasi yang seluas-luasnya. Dalam Islam Negara berada " didalam genggaman sekalian orang rakyat (umat) yang semuanya bertakluk dan menurut Satu Hukum yaitu Qur'an dan Hadist.

Pada umumnya PSI memikirkan pemecahan persoalan ekonomi dan social dengan menghubungkannya dengan pedoman-pedoman yang bersifat etis dan juga menolak perbedaan deraj manusia dalam pergaulan hidup bersama dan dalm hokum, mengakui persamaan harga antara laki-laki dan perempuan, dan antara suami-istri. Pendidikan hendaklah bersandarkan asas kebangsaan berdasrkan islam. 
Dalam bidang agama, pertai berusaha untuk tidak membesar-besarkanperselesihan khilafahnya serta perkat furu, karena perselisihan ini menyebabkan tumbuhnya perpecahan serta lemahnya umat. Ia menolak campur tangannya pihak bukan Islam dalam soal ibadat, dan menuntut hapusnya semua peraturan yang menghambat perkembangan Islam.

\section{Gerakan Muhammadiyah}

Gerakan Muhammadiyah merupakan sebuah organisasi social Islam di Indonesia sebelum PD II . Muhammadiyah merupakan lembaga pendidikan bersifat permanan yang didirikan 18 November 1912 oleh Kyai Haji Ahmad Dahlan di Yogyakarta yang merupakan saran dari murit-muritnya dan anggaota Budi Utomo .Organisasi ini dari tahun-tahun pertama tidak mengadakan pembagaian uelas antar anggota dalam kegiatannya, hal ini disebabkan oleh ruang gerak yang masih sangat terbatas( sekurang-kurangnya 1917) di daerah Kauman, Yogyakarta saja. Ahmad Dahlan aktif dalam bertabliq, mengajar di sekolah Muhammadiyah, memberikan bimbingan pada masyarakat agar melakukan kegiatan seperti shalat dan memberikan bantuan pada fakir miskin dengan mengumpulkan dana dan pakaian untuk mereka. Sifat social pendidikan dari Muhammadiyah memang sudah diletakkan saat ini.

Daerah operasi organisasi Muhammadiyah mulai diluaskan setelah tahun 1917, saat itu Budi Utomo melakukan kongres di Yogyakarta dan Ahmad Dahlan member keindahan kogres itu dengan melalui tabliq yang dilakukannya sehingga pengurus Muhammadiyah menerima permintaan dari berbagai tempat di Jawa untuk mendirikan cabang-cabang. Anggaran dasar organisasi ini yang membatasi diri dari pada kegiatankegiatan di Yogyakarta saja haruslah diubah. Hal itu dilakukan tahun 1920 saat bidang kegiatan Muhammadiyah diluaskan ke seluruh pulau Jawa dan tahun berikutnya (1921) ke seluruh Indonesia.

Perluasannya dipermudah dengan adanya beberapa factor. Ahmad Dahlan melakukan dengan cara mberpropoganda dengan mmperlihatkan toleransi dan pengertian kepada pendengarnya yang memberikan sambutan yang memuaskan. Masyarakat yang mengenal pembaharuan I Mesir melihat juga 
pada Muhammadiyah sebagai jalan untuk menyebarkan pemikiran-pemikiran pembaharuan di Indonesia. Pembaharuan yang mulanya dilakukan oleh Ahmad Dahlan yaitu : tentang praktek-pratek lahiriyah seperti kib;lat dan kebersihan, kebudian dirangsang oleh oemikiran dari pembaharu Mesir dan diperluaskan secara lambat laun pada masalah-masalh fundamental dari masyarakat dan umat Islam, selanjutnya tentang persoalan apakah ijthad telah tertutup atau masih terbuka.

Adapun langkah pembaruan yang bersifat "reformasi" ialah dalam merintis pendidikan "modern" yang memadukan pelajaran agama dan umum. Menurut Kuntowijoyo, gagasan pendidikan yang dipelopori Kyai Dahlan, merupakan pembaruan karena mampu mengintegrasikan aspek "iman" dan "kemajuan", sehingga dihasilkan sosok generasi muslim terpelajar yang mampu hidup di zaman modern tanpa terpecah kepribadiannya (Kuntowijoyo, 1985: 36). Lembaga pendidikan Islam "modern" bahkan menjadi ciri utama kelahiran dan perkembangan Muhammadiyah, yang membedakannya dari lembaga pondok pesantren kala itu. Pendidikan Islam "modern" itulah yang di belakang hari diadopsi dan menjadi lembaga pendidikan umat Islam secara umum.

Kepeloporan pembaruan Ahmad Dahlan yang menjadi tonggak berdirinya Muhammadiyah juga ditunjukkan dengan merintis gerakan perempuan 'Aisyiyah' tahun 1917, yang ide dasarnya dari pandangannya agar perempuan muslim tidak hanya berada di dalam rumah, tetapi harus giat di masyarakat dan secara khusus menanamkan ajaran Islam serta memajukan kehidupan kaum perempuan. Langkah pembaruan ini yang membedakan Ahmad Dahlan dari pembaru Islam lain, yang tidak dilakukan oleh Afghani, Abduh, Ahmad Khan, dan lainlain (mukti Ali, 2000: 349-353). Perintisan ini menunjukkan sikap dan visi Islam yang luas dari Ahmad Dahlan mengenai posisi dan peran perempuan, yang lahir dari pemahamannya yang cerdas dan bersemangat tajdid, padahal dari Kauman ini tidak bersentuhan dengan ide atau gerakan "feminisme" seperti berkembang sekarang ini. Artinya, betapa majunya pemikiran Kyai Dahlan yang kemudian melahirkan Muhammadiyah sebagai gerakan Islam murni yang berkemajuan. 
Kelahiran Muhammadiyah dengan gagasan-gagasan cerdas dan pembaruan dari pendirinya, Ahmad Dahlan, didorong oleh dan atas pergumulannya dalam menghadapi kenyataan hidup umat Islam dan masyarakat Indonesia kala itu, yang juga menjadi tantangan untuk dihadapi dan dipecahkan. Adapun faktor-faktor yang menjadi pendorong lahirnya Muhammadiyah ialah antara lain:

1. Umat Islam tidak memegang teguh tuntunan Al-Quran dan Sunnah Nabi, sehingga menyebabkan merajalelanya syirik, bid'ah, dan khurafat, yang mengakibatkan umat Islam tidak merupakan golongan yang terhormat dalam masyarakat, demikian pula agama Islam tidak memancarkan sinar kemurniannya lagi

2. Ketiadaan persatuan dan kesatuan di antara umat Islam, akibat dari tidak tegaknya ukhuwah Islamiyah serta ketiadaan suatu organisasi yang kuat;

3. Kegagalan dari sebagian lembaga-lembaga pendidikan Islam dalam memprodusir kader-kader Islam, karena tidak lagi dapat memenuhi tuntutan zaman;

4. Umat Islam kebanyakan hidup dalam alam fanatisme yang sempit, bertaklid buta serta berpikir secara dogmatis, berada dalam konservatisme, formalisme, dan tradisionalisme;

5. keinsyafan akan bahaya yang mengancam kehidupan dan pengaruh agama Islam, serta berhubung dengan kegiatan misi dan zending Kristen di Indonesia yang semakin menanamkan pengaruhnya di kalangan rakyat

\section{Gerakan Nahdatul Ulama}

Protes luar biasa pun muncul di Indonesia, ketika bulan Januari 1926 ulama-ulama Ahlussunnah wal Jammah di Indonesia berkumpul di Surabaya untuk membahas perubahan ajaran di dua kota suci itu. Dari pertemuan tersebut lahirlah panita Komite Hijaz yang diberi mandat untuk mengahadap raja Ibnu Sa'ud guna menyampaikan masukan dari ulama-ulama Ahlussunah wal Jamaah di Indonesia. Akan tetapi karena belum ada organisasi induk yang menaungi delegasi Komite Hijaz, maka pada tanggal 31 Januari 1926, ulama-ulama Ahlussunnah wal Jamaah Indonesia kembali berkumpul dan membentuk 
organisasi Induk yang diberi nama Nahdlatul Ulama dengan Rois Akbar KH. Hasyim Asy'ari. Setelah terbentuk, komite Hijaz mengirimkan delegasi sebagai utusan NU menghadap Raja Saudi. Delegasi yang dipimpin oleh KH. Wahab Hasbullah ini mengajukan protes atas langkah kerajaan Saudi yang meminggirkan madzhab empat, menggusur petilasan sejarah Islam, melarang tawassul, melarang ziarah kubur dan lainlainnya dengan alas an anti syirik dan bid'ah.

Kelahiran NU merupakan muara perjalanan panjang sejumlah ulama' pondok pesantren di awal abad 20 yang berusaha mengorganisir diri dan berjuang melestarikan ajaran Islam Ahlussunnah Waljamaah, sekaligus mengobarkan semangat nasionalisme melawan colonial Belanda.

Sesuai visinya, diharapkan NU menjadi wadah tatanan masyarakat yang sejahtera,berkeadilan dan demokratis bagi jutaan anggotanya. Hal ini diwujudkan dengan mengupayakan system kebijakan yang menjamin terwujudnya masyarakat sejahtera, melakukan pemberdayaan dan advokasi masyarakat serta menciptakan Ahlaqul Karimah.

\section{Budaya Islam Indonesia}

Agama Islam muncul pada Abad ke-6 M kemudian masuk ke Indonesia pada abad ke-7 $\mathrm{M}$ dan mulai berkembang pada abad ke-13 M. Perkembangan Islam di Indonesia hampir di seluruh Kepulauan Indonesia. Bertolak dari kenyataan tersebut, Islam banyak menghasilkan peninggalan sejarah yang bercorak Islam di Indonesia yang sangat beraneka ragam. Peninggalanpeninggalan itu antara lain sebagai berikut:

\section{Tempat Ibadah}

Dilihat dari segi arsitekturnya, masjid-masjid di Indonesia kuno menampilkan gaya arsitektur asli Indonesia, yakni dengan ciri-ciri sebagai berikut.
a. Atapnya bertingkat/tumpang dan ada puncaknya (mustaka).
b. Pondasinya kuat dan agak tinggi.
c. Ada serambi di depan atau di samping.
d. Ada kolam/parit di bagian depan atau samping. 
Gaya arsitektur bangunan yang mendapat pengaruh Islam ialah :
a. Hiasan kaligrafi.
b. Kubah.
c. Bentuk masjid.

Sejak masuk dan berkembangnya agama Islam di Indonesia banyak masjid didirikan dan termasuk masjid kuno, di antaranya masjid Demak, masjid Kudus, masjid Banten, masjid Cirebon, masjid Ternate, masjid Angke, dan sebagainya.

a. Masjid Angke

Masjid ini terletak di Jalan Tubagus Angke, Jakarta Barat yang dibangun pada abad ke-18. Masjid ini beratap tumpang dua. Masjid Angke merupakan masjid tua yang masih terlihat kekunoannya. Masjid ini memiliki gaya arsitektur dan hiasan yang cantik, merupakan perpaduan antara gaya Jawa, Cina, Arab, dan Eropa. Masjid ini dibangun pada tahun 1761. Pengaruh agama Islam menimbulkan tempat ibadah yang namanya bermacammacam. Tempat ibadah ukuran kecil disebut langgar, yang berukuran sedang disebut masjid, dan yang ukuran besar disebut masjid agung atau masjid jami. Masjid merupakan tempat peribadatan agama Islam (tempat orang melakukan salat). Masjid juga berperan sebagai tempat penggemblengan jiwa dan pribadi-pribadi Islam yang hidup di tengah-tengah masyarakat.

b. Masjid Demak

Masjid Demak didirikan pada masa pemerintahan Raden Patah. Bangunan masjid terletak di Kadilangu, Demak. Masjid ini beratap tumpang yang mirip dengan bentuk pura Hindu. Masjid Demak didirikan dengan bantuan para wali (walisongo). Pembangunan masjid dipimpin langsung oleh Sunan Kalijaga. Keunikan masjid ini terletak pada salah satu tiang utamanya, yakni terbuat dari bahan pecahan-pecahan kayu yang disebut tatal (soko tatal).

c. Masjid Kudus 
Masjid Kudus didirikan oleh Sunan Kudus. Bentuk bangunan masjid ini memiliki ciri khusus. Bagian menaranya menyerupai candi Hindu.

d. Masjid Banten

Masjid Banten didirikan pada abad ke-16. Bangunannya memiliki atap tumpang sebanyak lima tingkat. Kemungkinan model bangunan seperti ini untuk menggambarkan derajat yang dapat diraih seseorang dalam Islam. Menara masjid Banten dibangun oleh arsitektur Belanda bernama Cardel. Itulah sebabnya, menara tersebut bergaya Eropa menyerupai mercusuar.

e. Masjid Cirebon

Masjid Cirebon didirikan pada abad ke-16 M, ketika Kerajaan Cirebon berkuasa. Bentuk atap masjid Cirebon juga berupa atap tumpang, terdiri atas dua tingkat.

\section{Keraton}

Keraton berfungsi sebagai pusat pemerintahan dan sebagai tempat tinggal raja beserta keluarganya. Pada zaman kekuasaan Islam, didirikan cukup banyak keraton sesuai dengan perkembangan kerajaan Islam. Beberapa contoh keraton adalah sebagai berikut

a. Keraton Cirebon

Keraton Cirebon didirikan oleh Fatahillah atau Syarif Hidayatullah pada tahun 1636. Letaknya di kota Cirebon, Jawa Barat.

b. Istana Raja Gowa

Istana Raja Gowa terdapat di Sulawesi Selatan.

c. Istana Keraton Surakarta

Keraton Surakarta terbentuk berdasarkan perjanjian Giyanti pada tahun 1755. Keraton Surakarta sebelumnya merupakan wilayah Kerajaan Mataram dengan rajanya Paku Buwono III.

d. Keraton Yogyakarta

Semula Keraton Yogyakarta merupakan wilayah Kerajaan Mataram, kemudian berdasarkan perjanjian Giyanti pada tahun 1755 didirikan kerajaan Yogyakarta dengan rajanya yang pertama Sultan Hamengkubuwono I. 


\section{f. Istana Mangkunegaran}

Istana Mangkunegaran merupakan bangunan kerajaan yang terbentuk berdasarkan perjanjian Salatiga tahun 1757.

\section{Batu Nisan}

Batu nisan berfungsi sebagai tanda kubur. Tanda kubur yang terbuat dari batu bentuknya bermacam-macam. Pada bangunan batu nisan biasanya dihiasi ukir-ukiran dan kaligrafi. Kebudayaan batu nisan diduga berasal dari Perancis dan Gujarat. Di Indonesia, kebudayaan tersebut berakulturasi dengan kebudayaan setempat (India).

Beberapa batu nisan peninggalan sejarah di Indonesia antara lain sebagai berikut.

a. Batu Nisan Malik as-Saleh

Batu nisan ini dibangun di atas makam Sultan Malik asSaleh di Lhokseumawe, Aceh Utara. Sultan Malik asSaleh adalah raja pertama dari kerajaan Samudra Pasai.

b. Batu Nisan Ratu Nahrasiyah

Batu nisan ini dibangun di atas makam ratu Samudra Pasai bernama Nahrasiyah. Ia meninggal pada tahun 1428. Nisan itu dihiasi kaligrafi yang memuat kutipan Surat Yasin dan Ayat Kursi.

c. Batu Nisan Fatimah binti Maimun

Batu nisan ini dibuat sebagai tanda makam seorang wanita Islam yang bernama Fatimah binti Maimun. Batu nisan ini terdapat di Leran, Gresik, Jawa Timur.

d. Batu Nisan Sultan Hasanuddin

Batu nisan ini dibangun di atas makam raja Makasar. Makam Sultan Hasanuddin berada dalam satu kompleks dengan pemakaman raja-raja Gowa dan Tallo.

Pada makam tersebut, dibuat cungkup berbentuk kijing. Cungkup itu terbuat dari batu berbentuk prisma. Kemudian batu itu disusun berbentuk limas. Bangunan limas terpasang dengan alas berbentuk kubus dan di dalamnya terdapat ruangan. Pada ruangan inilah terdapat makam beserta batu nisan. 


\section{Kaligrafi}

Pada mulanya kaligrafi merupakan akulturasi antara budaya Hindu dengan budaya Islam. Namun dalam perkembangannya, dengan makin kuatnya rasa keagamaan maka unsur Hindu makin berkurang; sehingga wujudnya adalah orang yang sedang shalat atau dalam wujud masjid yang menggunakan huruf Arab.

Kaligrafi adalah seni menulis Arab yang indah tanpa tanda garis (harakat). Seni kaligrafi yang bernafaskan Islam merupakan rangkaian dari ayat-ayat suci Al Quran. Tulisan tersebut dirangkai sedemikian rupa sehingga membentuk gambar, misalnya binatang, daun-daunan, bunga atau sulur, tokoh wayang dan sebagainya.

Contoh kaligrafi antara lain sebagai berikut.

a. Kaligrafi pada batu nisan.

b. Kaligrafi bentuk wayang dari Cirebon.

c. Kaligrafi bentuk hiasan.

\section{Seni Pahat}

Seni pahat seiring dengan kaligrafi. Seni pahat atau seni ukir berasal dari Jepara, kota awal berkembangnya agama Islam di Jawa yang sangat terkenal. Di dinding depan masjid Mantingan (Jepara) terdapat seni pahat yang sepintas lalu merupakan pahatan tanaman yang dalam bahasa seninya disebut gaya arabesk, tetapi jika diteliiti dengan saksama di dalamnya terdapat pahatan kera. Di Cirebon malahan ada pahatan harimau. Dengan demikian, dapat dimengerti bahwa seni pahat di kedua daerah tersebut (Jepara dan Cirebon), merupakan akulturasi antara budaya Hindu dengan budaya Islam.

\section{Seni Pertunjukan}

Di antara seni pertunjukan yang merupakan seni Islam adalah seni suara dan seni tari. Seni suara merupakan seni pertunjukan yang berisi salawat Nabi dengan iringan rebana. Dalam pergelarannya para peserta terdiri atas kaum pria duduk di lantai dengan membawakan lagu-lagu berisi pujian untuk Nabi Muhammad Saw. yang dibawakan secara lunak, namun iringan rebananya terasa dominan. Peserta 
mengenakan pakaian model Indonesia yang sejalan dengan ajaran Islam, seperti peci, baju tutup, dan sarung.

\section{Tradisi atau Upacara}

Tradisi atau upacara yang merupakan peninggalan Islam di antaranya ialah Gerebeg Maulud. Perayaan Gerebeg, dilihat dari tujuan dan waktunya merupakan budaya Islam. Akan tetapi, adanya gunungan ( tumpeng besar) dan iring-iringan gamelan menunjukkan budaya sebelumnya (Hindu Buddha). Kenduri Sultan tersebut dikeramatkan oleh penduduk yang yakin bahwa berkahnya sangat besar, yang menunjukkan bahwa animismedinamisme masih ada. Hal ini dikuatkan lagi dengan adanya upacara pembersihan barang-barang pusaka keraton seperti senjata (tombak dan keris) dan kereta. Upacara semacam ini masih kita dapatkan di bekas-bekas kerajaan Islam, seperti di Keraton Cirebon dan Keraton Surakarta.

Di keraton Surakarta upacara pembersihan barangbarang pusaka di kenal dengan "jamasan pusaka" yang dilakukan pada malam 1 Muharam/Suro sehingga dikenal Tradisi Sura. Acara jamasan pusaka kemudian dilanjutkan dengan upacara kirab, salah satunya adalah upacara kirab pusaka, seperti Pusaka Kanjeng Kyai Slamet, merupakan sebuah simbolisasi dari keinginan untuk mendapatkan keselamatan, kesejahteraan, dan kebahagiaan hidup baik lahir maupun batin. Sebagai cucuk lampah dalam acara kirab tersebut adalah kerbau bule keturunan Kanjeng Kyai Slamet, salah satu klangenan peninggalan Sri Susuhunan Paku Buwono $\mathrm{X}$ dan 10 pusaka yang diperintahkan untuk dikirabkan pada pergantian tahun baru (malam 1 Sura). Konon menurut kepercayaan masyarakat Jawa, kerbau adalah salah satu hewan yang dianggap memiliki tuah tersendiri sebagai tolak bala untuk mengusir segala bencana.

\section{Karya Sastra}

Pengaruh Islam dalam sastra Melayu tidak langsung dari Arab, tetapi melalui Persia dan India yang dibawa oleh orang-orang Gujarat. Dengan demikian, sastra Islam yang 
masuk ke Indonesia sudah mendapat pangaruh dari Persia dan India.

Meskipun menurut sejarah, Persia dan India ditaklukkan oleh Islam, namun kebudayaan dari kedua negara tersebut lebih besar pengaruhnya. Karya sastra masa Islam banyak sekali macamnya, antara lain sebagai berikut.

a. Babad ialah cerita berlatar belakang sejarah yang lebih banyak di bumbui dengan dongeng. Contohnya: Babad Tanah Jawi, Babad Demak, Babad Giyanti, dan sebagainya.

1) Babad Tanah Jawi

Kitab ini berisi silsilah raja-raja Jawa dimulai dari Nabi Adam sampai dengan Bathara Guru. Bathara Guru bertakhta di Suralaya berputra lima orang di antaranya adalah Bathara Wisnu yang kemudian turun ke dunia menjadi raja pertama di Pulau Jawa dengan gelar Prabu Set. Jadi, Bathara Wisnulah yang menurunkan raja-raja Jawa.

2) Babad Demak

Kitab ini berisi tentang kisah berdirinya Kerajaan Demak yang dipelopori oleh Raden Patah dan Wali Songo. Sebelum Kerajaan Demak berdiri, telah ada tanda-tanda yaitu pindahnya sinar cahaya kekuasaan dari Majapahit ke Demak.

3) Babad Giyanti

Kitab ini berisi tentang perjuangan Pangeran Mangkubumi di Surakarta sampai dinobatkannya menjadi Sultan Hamengku Buwono I di Yogyakarta.

b. Hikayat ialah karya sastra yang berupa cerita atau dongeng yang dibuat sebagai sarana pelipur lara atau pembangkit semangat juang. Contoh, Hikayat Sri Rama, Hikayat Hang Tuah, Hikayat Amir Hamzah dan sebagainya.

1) Hikayat Sri Rama

Hikayat ini merupakan saduran dari Kitab Ramayana. Isinya men- ceritakan tentang riwayat Rama sejak lahir kemudian berperang melawan Rawana raja Alengka untuk memperebutkan Shinta, istrinya. Dalam peperangan ini Rama dibantu oleh 
prajurit kera yang dipimpin oleh Sugriwa. Dewi Shinta berhasil direbut dari tangan Rawana dan segera dibawa ke Ayodya. Namun, Rama menyangsikan kesucian Shinta yang telah lama berada di Alengka, sehingga ia dikucilkan di Pertapaan Walmiki. Untuk membuktikan kesucian Shinta, Shinta ingin bunuh diri dengan cara membakar diri (pati obong). Namun, karena Sinta benar-benar suci tidak tersentuh oleh Rawana maka dewa melindunginya. Rama akhinya menerima kembali dan kemudian diboyong ke Ayodya. (bandingkan dengan cerita Rama Shinta dalam Balet Ramayana yang dipentaskan di Candi Prambanan setiap bulan Purnama).

2) Hikayat Hang Tuah

Hang Tuah, adalah orang yang bertuah. Tuah berarti bahagia dan selamat. Laksamana berarti mempunyai tanda atau keutamaan. Dengan demikian, hikayat ini berisi tentang kesetiaan dan keperwiraan seorang laksamana Kerajaan Malaka bernama Hang Tuah bersama empat orang sahabatnya, yakni Hang Jebat, Hang Lekir, Hang Lekiu, dan Hang Kesturi yang berhasil menjadi orang besar.

3) Hikayat Amir Hamzah

Hikayat ini berasal dari Timur Tengah setelah masuk ke Indonesia

(Jawa) mendapat banyak tambahan dan disesuaikan dengan kebudayaan Jawa sehingga dikenal dengan Serat Menak. Tokohnya adalah Amir Hamzah yang di masyarakat Jawa disebut Wong Agung Menak atau Wong Agung Jayenglono. Inti ceritanya adalah adanya peperangan antara Amir Hamzah dengan mertuanya yang masih kafir yakni Raja Nursewan dari Kerajaan Madayin. Peperangan ini bisa terjadi akibat akal licik dan fitnah dari Patih Bestak dari Kerajaan Madayin.

c. Syair ialah puisi lama yang tiap-tiap bait terdiri atas empat baris yang berakhir dengan bunyi yang sama. 
Contoh: Syair Abdul Muluk, Syair Ken Tambuhan, dan Gurindam Dua Belas.

1) Syair Abdul Muluk

Syair ini menceritakan tentang adanya Raja Abdul Muluk dari Kerajaan Barbari yang mempunyai dua orang istri yakni Siti Rahmah dan Siti Rafiah. Sewaktu negerinya diserang raja Hindustan, seluruh penghuni istana dapat ditawan, namun Siti Rafiah berhasil meloloskan diri. Dengan perjuangan yang gigih, akhirnya Siti Rafiah berhasil merebut kembali Kerajaan Barbari.

2) Syair Ken Tambuhan

Syair ini menceritakan tentang adanya percintaan antara Raden Inu Kertapati putra mahkota kerajaan Kahuripan dengan Ken Tambuhan, (putri Jangung Pura) yang dijumpai di hutan. Baginda permaisuri bermaksud untuk menikahkan Inu Kertapati dengan putri Banjarkulon yang sepadan. Atas perintah permaisurinya, Ken Tambuhan berhasil dibunuh dan mayatnya dihanyutkan ke sungai dengan rakit. Mayat itu ditemukan oleh Inu Kertapati. Inu Kertapati sangat berduka cita atas kematian Ken Tambuhan, ia membelanya dengan jalan bunuh diri.

3) Syair Gurindam Duabelas

Gurindam bentuknya puisi yang aturannya sedikit lebih bebas daripada puisi. Gurindam Dua Belas ditulis oleh Raja Ali Haji, isinya menceritakan tentang nasihat bagi semua orang, agar menjadi orang yang dihormati dan disegani. Selain itu, Gurindam Dua Belas juga berisi petunjuk bagaimana orang dapat mengekang diri dari segala macam nafsu duniawi.

d. Suluk adalah kitab-kitab yang berisi ajaran Tasawuf, sifatnya pantheistis, yaitu manusia menyatu dengan Tuhan. Tasawuf juga sering dihubungkan dengan pengertian suluk yang artinya perjalanan. Alasannya, para sufi sering mengembara dari satu tempat ke tempat lain. Di Indonesia, suluk oleh para ahli tasawuf dipakai dalam arti karangan prosa maupun puisi. Istilah suluk 
kadang-kadang dihubungkan dengan tindakan zikir dan tirakat. Suluk yang terkenal, di antaranya:

1) Suluk Sukarsah

Isinya menceritakan Ki Sukarsa yang mencari ilmu sejati untuk men- dapatkan kesempurnaan. Dalam uraiannya, tampak banyak persamaan dengan cerita Dewa Ruci, yaitu sewaktu Bima berguru kepada begawan Dorna (dalam cerita pewayangan "Bima Mencari Air Suci).

2) Suluk Wijil

Isinya mengenai wejangan-wejangan Sunan Bonang kepada Wijil. Wijil adalah seorang kerdil bekas abdi raja Majapahit.

3) Suluk Malang Semirang

Isinya menceritakan tentang orang yang telah mencapai kesempurnaan, lepas dari ikatan-ikatan syari'ah dan berhasil menyatu dengan Tuhan (bandingkan dengan reinkarnasi dalam ajaran Hindu).

\section{Kesimpulan}

Pada Tahun 70-an-80-an gerakan-gerakan Islam di Indonesia mulai mengalami perubahan yang tidak hanya didominasi oleh gerakan-gerakan pada tahun 20an-30an yang sebelum mengalami kemerdekaan. Gerakan pada tahun yang dimulai dari tahun 70-an sering disebut dengan gerakan kontemporer, yaitu gerakan yang muncul dalam suatu setting kehidupan masyarakat Indonesia yang sedang mengalami proses intensifikasi modernisasi.

Dari penjelasan di atas dapat di ambil benang merah, bahwasannya gerakan-gerakan sosial modern Islam yang ada di indonesia meliputi Gerakan Serikat Islam, Gerakan Muhammadiyyah, dan Gerakan Nahdlatul Ulama.

Agama Islam muncul pada Abad ke-6 M kemudian masuk ke Indonesia pada abad ke-7 $\mathrm{M}$ dan mulai berkembang pada abad ke-13 M. Perkembangan Islam di Indonesia hampir di seluruh Kepulauan Indonesia. Bertolak dari kenyataan tersebut, Islam banyak menghasilkan peninggalan sejarah yang bercorak Islam di Indonesia yang sangat beraneka ragam. Peninggalan- 
peninggalan itu antara lain, tempat ibadah, keraton, batu nisan, kaligrafi, seni pahat, seni pertunjukan, tradisi upacara, dan karya sastra. 


\section{DAFTAR PUSTAKA}

Noer, D. Gerakan Modern Islam Di Indonesia 1900-1942. Jakarta : PT Djaya Pirusa, 1980.

Kuntowijoyo. Dinamika Sejarah Umat Islam Indonesia. Yogyakarta : Pustaka Pelajar Offset, 1994.

Abdul Aziz. Ed. Dkk. Gerakan Islam Kotemporer Di Indonesia. Jakarta : Diva Pustaka Jakarta 2004. 